\title{
Hydrogen Evolution at Liquid|Liquid Interfaces Catalysed by 2D Materials
}

DOI:

10.1002/cnma.201700047

\section{Document Version}

Accepted author manuscript

Link to publication record in Manchester Research Explorer

\section{Citation for published version (APA):}

Hirunpinyopas, W., Rodgers, A., Worrall, S., Bissett, M., \& Dryfe, R. (2017). Hydrogen Evolution at Liquid|Liquid Interfaces Catalysed by 2D Materials. ChemNanoMat. https://doi.org/10.1002/cnma.201700047

\section{Published in:}

ChemNanoMat

\section{Citing this paper}

Please note that where the full-text provided on Manchester Research Explorer is the Author Accepted Manuscript or Proof version this may differ from the final Published version. If citing, it is advised that you check and use the publisher's definitive version.

\section{General rights}

Copyright and moral rights for the publications made accessible in the Research Explorer are retained by the authors and/or other copyright owners and it is a condition of accessing publications that users recognise and abide by the legal requirements associated with these rights.

\section{Takedown policy}

If you believe that this document breaches copyright please refer to the University of Manchester's Takedown Procedures [http://man.ac.uk/04Y6Bo] or contact uml.scholarlycommunications@manchester.ac.uk providing relevant details, so we can investigate your claim.

\section{OPEN ACCESS}




\section{CHEMNANOMAT}

CHEMISTRY OF NANOMATERIALS FOR ENERGY, BIOLOGY AND MORE

www.chemnanomat.org

\section{Accepted Article}

Title: Hydrogen Evolution at Liquid|Liquid interfaces catalysed by 2D materials

Authors: Robert A.W. Dryfe, Wisit Hirunpinyopas, Andrew Rodgers, Stephen Worrall, and Mark Bissett

This manuscript has been accepted after peer review and appears as an Accepted Article online prior to editing, proofing, and formal publication of the final Version of Record (VoR). This work is currently citable by using the Digital Object Identifier (DOI) given below. The VoR will be published online in Early View as soon as possible and may be different to this Accepted Article as a result of editing. Readers should obtain the VoR from the journal website shown below when it is published to ensure accuracy of information. The authors are responsible for the content of this Accepted Article.

To be cited as: ChemNanoMat 10.1002/cnma.201700047

Link to VoR: http://dx.doi.org/10.1002/cnma.201700047 


\section{Hydrogen Evolution at Liquid|Liquid Interfaces Catalysed by 2D Materials}

Wisit Hirunpinyopas, ${ }^{[\mathrm{a}]}$ Andrew N.J. Rodgers, ${ }^{[\mathrm{a}]}$ Stephen D. Worrall, ${ }^{[\mathrm{b}]}$ Mark A. Bissett, ${ }^{[\mathrm{c}]}$ Robert A.W. Dryfe ${ }^{[\mathrm{a}]^{*}}$

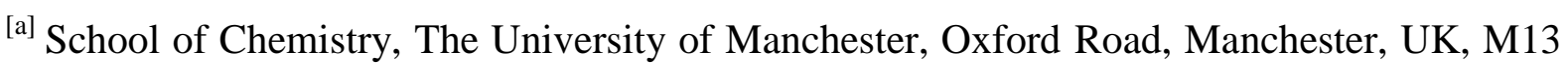
9PL

${ }^{[b]}$ School of Earth and Environmental Science, The University of Manchester, Oxford Road, Manchester, UK, M13 9PL

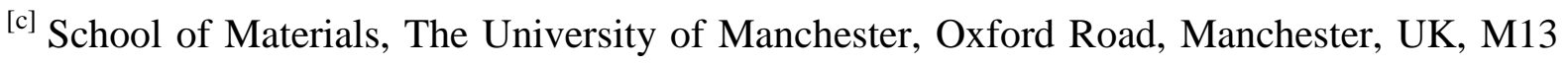
9PL

*Corresponding author: robert.dryfe@ manchester.ac.uk 


\begin{abstract}
The hydrogen evolution reaction (HER) plays a crucial role in clean energy production in hydrogen fuel cells. In order to utilise this process effectively, new catalysts are required that are cheap, non-toxic and efficient. In this context, 2D materials such as transition metal dichalcogenides (e.g. $\mathrm{MoS}_{2}$ ) should offer the desired properties but have so far proven difficult to manufacture into useful devices. In this work, liquid|liquid interfaces are used for the assembly and testing of the catalytic efficiency of a number of $2 \mathrm{D}$ materials and their composites, exploiting the ability of the materials to self-assemble at these interfaces and be tested electrochemically in situ. $\mathrm{MoS}_{2}, \mathrm{WS}_{2}$, and graphene were developed for hydrogen evolution at the water|1,2-dichlorobenzene (DCB) interface. The exfoliation process was carried out in DCB and resulted in multi-layer $\mathrm{MoS}_{2}$, few layer $\mathrm{WS}_{2}$ and graphene: when assembled at the water|DCB interface, these materials acted as efficient HER catalysts. HER was investigated using voltammetry, with bulk reaction kinetics monitored by in-situ UVvisible spectroscopy at a constant potential. $\mathrm{MoS}_{2}$ exhibited the highest performance of the catalysts examined, with an average rate constant of $0.0132 \pm 0.063 \mathrm{~min}^{-1}$ at an applied Galvani potential of $+0.5 \mathrm{~V}$. This is ascribed to the sulphur edge sites of $\mathrm{MoS}_{2}$, which are known to be active for hydrogen evolution predominantly.
\end{abstract}

Keywords: liquid|liquid interface, Hydrogen evolution, Exfoliated transition metal dichalcogenides. 


\section{Introduction}

Two-dimensional materials (2D materials) have been widely studied over the past decade since the isolation of single atomic layers of graphite, known as graphene, using mechanical exfoliation in 2004. ${ }^{[1]}$ Graphene has attracted attention for a variety of potential applications. Following on from the successful isolation of graphene, other 2D materials have subsequently been reported as offering similarly promising properties: single-layered 2D transition metal dichalcogenides (2D TMDs) such as $\mathrm{MoS}_{2}, \mathrm{MoSe}_{2}, \mathrm{WS}_{2}, \mathrm{WSe}_{2}$, and $\mathrm{TiS}_{2}$, etc., are atomically thin semiconductor layers with the formula $\mathrm{MX}_{2}$, where $\mathrm{M}$ is the transition metal (e.g. Mo, W and Ti, etc.) and $\mathrm{X}$ is the chalcogen (e.g. S, Se, and Te, etc.). In the layered structure, one layer of TMDs consists typically of metal atoms sandwiched between two layers of chalcogen atoms by a covalent bond ( $\mathrm{M}-\mathrm{X}$ bonds); whereas the sandwiched layers are weakly bound by van der Waals forces thus enabling simple cleavage of the layers. ${ }^{[2]}$ Due to their crystal structures and wide range of chemical and physical properties, layered TMDs have attracted much interest in fundamental research and specific applications such as energy storage devices (e.g. Li-ion batteries, supercapacitors, fuel cells), or optoelectronic devices (e.g. lasers, photodetectors, light-emitting diodes (LEDs), solar cells), and as catalysts for the hydrogen evolution reaction (HER). ${ }^{[2 a, 2 b, 3]}$

The latter process, in particular the electrochemical hydrogen evolution reaction (HER, i.e. $2 \mathrm{H}^{+}+2 \mathrm{e}^{-} \rightarrow \mathrm{H}_{2}$ ), has been the focus of much activity since it requires efficient catalysts such as Pt, which support a high current density at low overpotentials in order to reduce protons easily. However, Pt catalysts are dramatically limited in large-scale applications because of their low abundance and high cost. Therefore, alternative electrocatalysts (e.g. $\mathrm{MoS}_{2}$ ) which behave similarly to Pt-group metals and are abundant and therefore available at low cost are crucial for development of future applications. ${ }^{[4]}$ The basis of the favourable exchange current density has been rationalised in terms of the Gibbs energy 
of the metal-hydrogen bond $\left(\Delta G_{H}{ }^{*}\right)$ on the edges sites of $\mathrm{MoS}_{2}$ calculated by using density functional methods. The observed trend follows a "volcano" plot, ${ }^{[5]}$ with a catalytic activity for $\mathrm{MoS}_{2}$ which is slightly below those of the Pt group metals (e.g. Pt, Pd, Rh, and Ir), which indicates that the increase of sulphide terminated Mo-edge are the predominant active sites for the HER. ${ }^{[5-6]}$

The interface between two immiscible electrolyte solutions (ITIES) has been studied as a "soft" interface for many applications including ion-selective sensors, ${ }^{[7]}$ macromolecule detectors ${ }^{[8]}$ and the electrochemical study of drugs partitioning at liquid|liquid interfaces. ${ }^{[9]}$ The ITIES is controlled by applying a potential across the interface, known as the Galvani potential difference, in order to study a variety of charge transfer reactions (e.g. ion transfer, heterogeneous electron transfer, or proton coupled electron transfer [PCET]). ${ }^{[10]}$ In this approach, electrochemistry at the ITIES has been extended to study the HER by pumping protons across the interface (homogeneous mechanism), as well as adsorbing catalyst at the ITIES to increase the HER rate (heterogeneous mechanism) coupled with electron transfer from organic phase reducing agents such as cobaltocene, osmocene, and decamethylferrocene (DcMFc) to produce molecular hydrogen. ${ }^{[3 \mathrm{~b}, 11]}$ The approach exploits the ability of liquid|liquid interfaces to assemble solid (nano-)materials such as metallic nanoparticles (OD or 3D), nanotubes/rods (1D), and graphene/TMDs (2D). ${ }^{[12]}$ Together this means that the electrochemistry at the ITIES is the ideal method for studying the catalytic efficiency of $2 \mathrm{D}$ materials such as TMDs towards the HER.

Recently, a number of reports have described the modification of ITIES systems with nanoparticles (e.g. $\mathrm{MoS}_{2}, \mathrm{MoB}, \mathrm{WS}_{2}$, and $\mathrm{Cu}_{2} \mathrm{WS}_{4}$ ), which act as catalysts for the evolution of hydrogen. ${ }^{[4 \mathrm{~b}, 11 \mathrm{a}, 13]}$ In these studies, the catalysts were suspended in the aqueous phase and floated at the interface forming catalytic rafts. However, the uniformity of the particle distribution, particularly at the interface, was not clear. The materials tended to agglomerate 
close to the cell walls, which makes it difficult to distinguish between the homogeneous and heterogeneous mechanisms. In these studies, 1,2-dichloroethane (DCE) was generally used as the organic phase for HER at the interface. ${ }^{[4 b, 11 a-c, 13-14]}$ This solvent has substantial drawbacks such as its toxicity, flammability, and possible carcinogenic effects, which preclude its use in industry. Here 1,2-dichlorobenzene (DCB) is used as an alternative organic solvent: as well as its larger potential window (ca. $1.0 \mathrm{~V}$ compared to $0.70 \mathrm{~V}$ for $\mathrm{DCE}),{ }^{[15]} \mathrm{DCB}$ is less toxic and has been previously reported to be a suitable solvent for the liquid-phase exfoliation of 2D materials. ${ }^{[16]}$ For this reason, DCB was used as the organic phase in our catalytic experiments at the ITIES, having first been used to exfoliate and selfassemble the $2 \mathrm{D}$ materials at the water|DCB interface, which gives the uniform distribution of materials at the interface. ${ }^{[17]}$ The resultant catalytic process was assessed in this work by four-electrode voltammetry for the different charge transfer reactions, combined with in situ UV-visible spectrophotometry for the kinetic studies. Furthermore, the structures of the adsorbed 2D materials at the interface were characterised by Raman spectroscopy, electron microscopy, and optical microscopy, as a ready means to characterise the material in situ at the interface, in addition to ex situ characterisation via powder X-ray diffraction and X-ray photoelectron spectroscopy in order to study the physical/chemical interactions and the changes in morphology at the ITIES.

\section{Results and Discussion}

The liquid|liquid electrochemical experiments were performed using the cell shown in Figure 1(a). Both aqueous and organic solutions were separately degassed using bath ultrasonication for 20 minutes followed by purging with nitrogen gas for 10 minutes. Additionally, preparation of the liquid|liquid interfaces from the constituent solvents was done under an argon atmosphere in order to avoid oxygen exposure. The electrochemical cell was placed 
inside a beaker which was kept under a constant flow of argon gas. In all experiments, the organic solution is the lower (i.e. higher density) phase. The general cell conditions used are shown, schematically, in Figure 1. Two separate Pt counter electrodes were used, with one each immersed in the aqueous and organic phases and $\mathrm{Ag} / \mathrm{AgCl}$ reference electrodes were used in each phase, connected to the main cell by Luggin capillaries. ${ }^{[18]}$ The surface area of the interface was $\sim 0.64 \mathrm{~cm}^{2}$. Tetraethylammonium cation $\left(\mathrm{TEA}^{+}\right.$, formal ion transfer potential $=0.116 \mathrm{~V}$ in $\mathrm{DCB}$ ) was used to convert the applied potential to Galvani potential differences, using the tetraphenylarsonium tetraphenylborate assumption. ${ }^{[19]}$

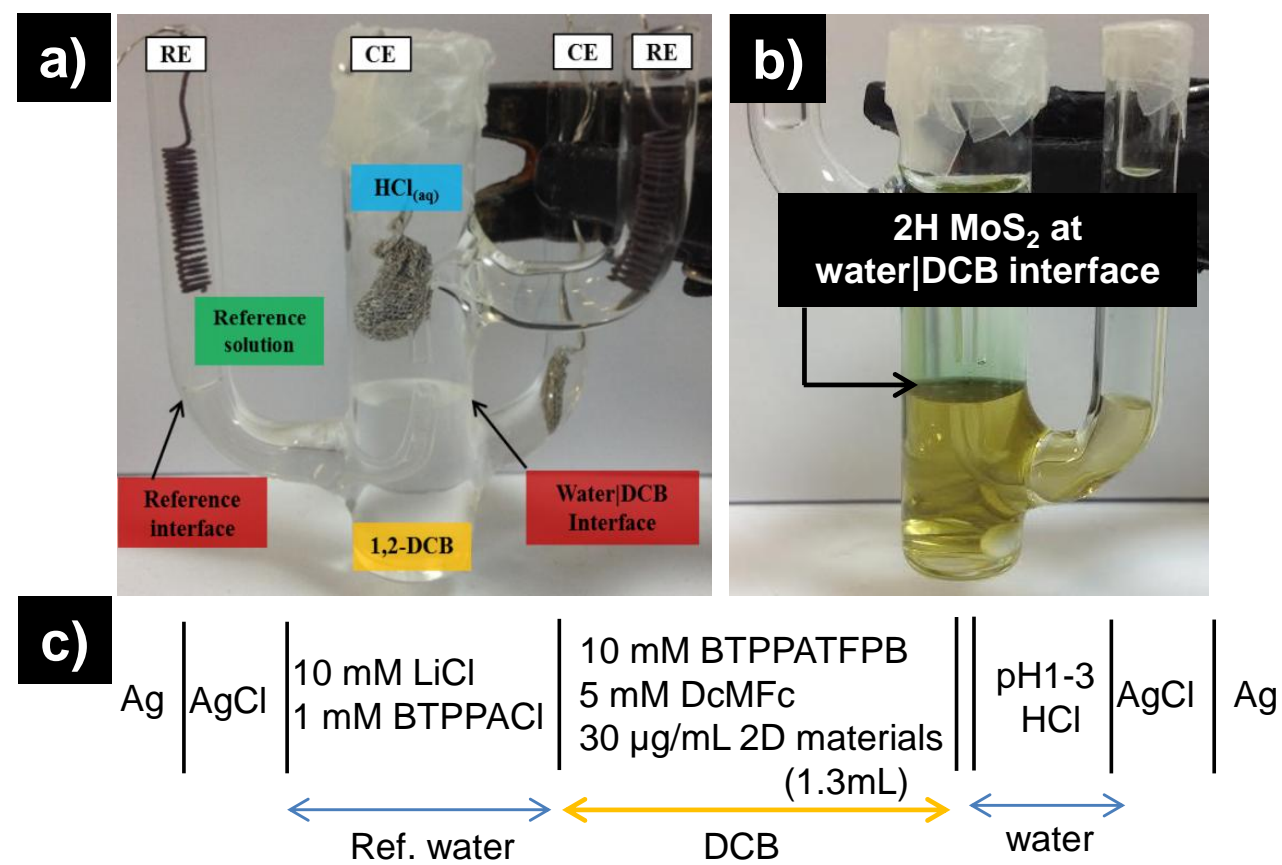

Figure 1. (a) Photograph of the water|DCB cell: $\mathrm{RE}$ - reference electrode ( $\mathrm{Ag} / \mathrm{AgCl}$ wires), $\mathrm{CE}$ - counter electrode (Pt wires). (b) Photograph of the cell, post electrolysis, with adsorbed $\mathrm{MoS}_{2}$ at the interface. (c) The general ITIES cell composition for the HER catalysed by exfoliated materials. The exact catalyst material composition is specified in each instance.

Figure 2(a) shows the dispersions of $\mathrm{MoS}_{2}, \mathrm{WS}_{2}$, and graphene in DCB with high stability of the dispersion, no aggregation over a few months was inferred from the appearance of the dispersion. These dispersions were investigated via their UV-visible 
absorbance as shown in Figure 2(b). The excitonic absorbance peaks in the spectrum corresponding to the transition between band gap energy in the exfoliated flakes were measured as followed: $1.85 \mathrm{eV}$ and $2.04 \mathrm{eV}$ for $\mathrm{MoS}_{2}, 1.98 \mathrm{eV}$ for $\mathrm{WS}_{2}$ in agreement with the literature. ${ }^{[20]}$ In the case of graphene, there is no excitonic absorption between 450 and 850 $\mathrm{nm}$, but the absorbance $\left(\lambda_{\max }\right.$ at $\left.660 \mathrm{~nm}\right)$ increased with the concentration because of the restoration of $\mathrm{C}=\mathrm{C}$ bonds in graphene sheets. ${ }^{[21]}$
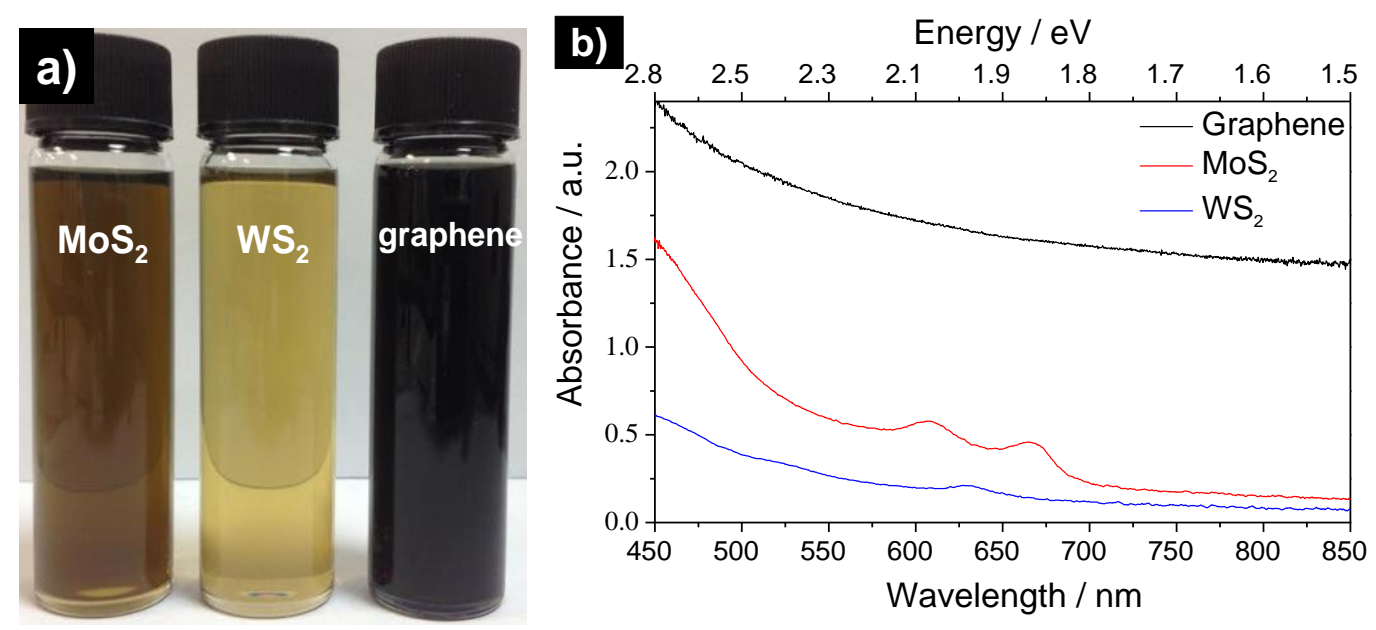

Figure 2. (a) Photographs and (b) UV-visible absorption spectra of the $\mathrm{MoS}_{2}, \mathrm{WS}_{2}$, and graphene dispersions in DCB.

The exfoliated $\mathrm{MoS}_{2}, \mathrm{WS}_{2}$, and graphene were filtered through $0.1 \mu \mathrm{m}$ PTFE membranes and dried overnight before performing powder X-ray diffraction (PXRD) analysis. These exfoliated materials supported on membranes were investigated for any change in crystal structure after exfoliation (e.g. peak position at (002) and d-spacings) by PXRD. Figure 3 shows PXRD patterns of the three materials before, and after, exfoliation. The peak separation and the corresponding, calculated d-spacings are displayed in Table 1. It can be clearly seen that the calculated d-spacing of the exfoliated materials are slightly bigger than those of the bulk materials because of the restacking of the layered materials during filtration, with residual solvent trapped between layers. ${ }^{[22]}$ Moreover, this explanation could 
be related to self-assembly of exfoliated materials at water|DCB interfaces that allowed material restacking at soft interfaces.

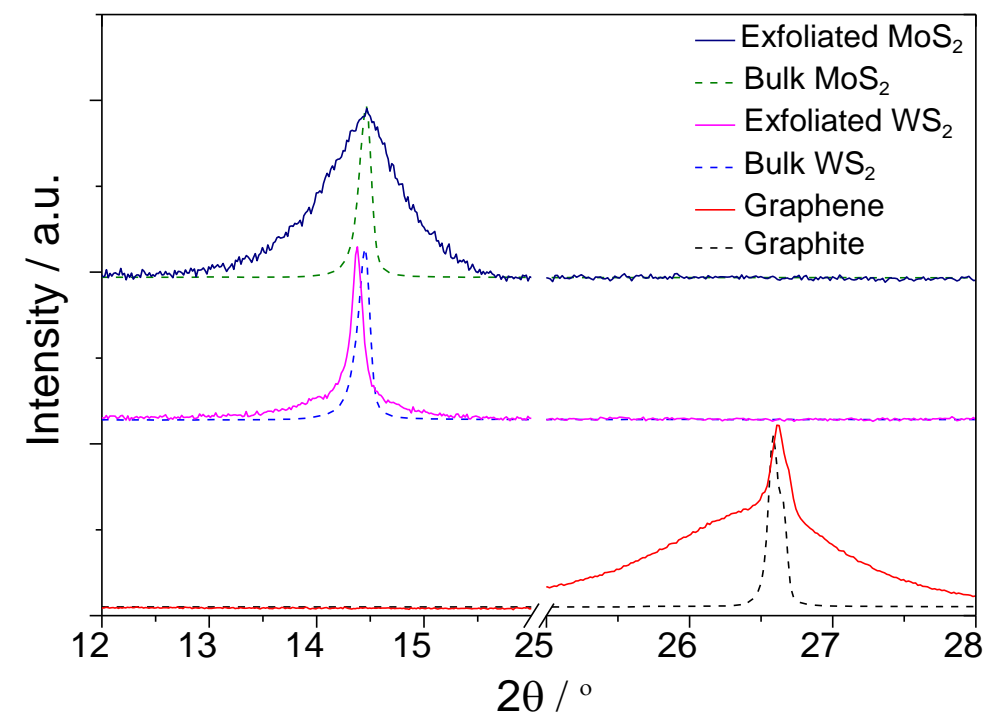

Figure 3. PXRD of the (002) peak position of the three materials as bulk materials (dashed line) and after exfoliation (solid line). Peak position of PTFE, $2 \theta=18.11^{\circ}$, was used as reference peak position (see full PXRD in Figure S5).

Table 1. Peak position (002) and calculated d-spacing for $\mathrm{MoS}_{2}, \mathrm{WS}_{2}$, and graphene.

\begin{tabular}{|c|c|c|c|c|c|c|}
\hline \multirow[t]{2}{*}{ Materials } & \multicolumn{2}{|c|}{$\begin{array}{c}\text { Position } \\
\text { of }(002) \text { reflection } /^{\circ}\end{array}$} & \multicolumn{2}{|c|}{ Calculated d-spacing /A } & \multicolumn{2}{|c|}{ FWHM $(2 \theta) /^{\circ}$} \\
\hline & Exfoliation & Bulk & Exfoliation & Bulk & Exfoliation & Bulk \\
\hline $\mathbf{M o S}_{2}$ & 14.42 & 14.45 & 6.14 & 6.13 & 0.36 & 0.05 \\
\hline $\mathbf{W S}_{2}$ & 14.37 & 14.43 & 6.16 & 6.14 & 0.09 & 0.05 \\
\hline Graphene & 26.46 & 26.59 & 3.37 & 3.35 & 0.55 & 0.04 \\
\hline
\end{tabular}

To investigate the properties of the individual exfoliated flakes, the dispersions of materials in DCB were deposited onto a $300 \mathrm{~nm}$ thick $\mathrm{Si} / \mathrm{SiO}_{2}$ wafer by spin coating at 6000 rpm to avoid restacking and aggregation of flakes. Those samples were then cleaned with acetone to remove any residual solvent. Raman spectroscopy, used as a non-destructive and fast characterisation method, plays a crucial role in analysing the electronic and physical structure of 2D materials such as the number of layers, the presence of strain, doping, and any 
defects. ${ }^{[23]}$ Raman spectroscopy indicates that the exfoliated materials were predominantly multi- layers for $\mathrm{MoS}_{2}$, but few-layer for $\mathrm{WS}_{2}$ and graphene (see Figure S6-8).

Figure 4 shows the most intense Raman peaks of the exfoliated materials after transfer from the water|DCB interface to a $\mathrm{Si} / \mathrm{SiO}_{2}$ wafer. The main peaks of $\mathrm{WS}_{2}$ consist of the $\mathrm{A}_{1 \mathrm{~g}}$ mode $\left(421.7 \mathrm{~cm}^{-1}\right)$, overlapping between the $2 \mathrm{LA}$ and $\mathrm{E}_{2 \mathrm{~g}}^{1}\left(352.2 \mathrm{~cm}^{-1}\right) .{ }^{[24]}$ The characteristic Raman spectral features of $\mathrm{MoS}_{2}$ are the in-plane $\mathrm{E}_{2 \mathrm{~g}}^{1}\left(383.8 \mathrm{~cm}^{-1}\right)$ and the out-of-plane $\mathrm{A}_{1 \mathrm{~g}}$ $\left(408.6 \mathrm{~cm}^{-1}\right)$, indicating multi-layer $(\geq 6)$ flakes. ${ }^{[25]}$ Graphene has a high intensity $G$ band at $1580 \mathrm{~cm}^{-1}$ with a shoulder peak ( $D^{\prime}$ peak), $D$ band at $1351 \mathrm{~cm}^{-1}$, and a low intensity $2 D$ band at $2720 \mathrm{~cm}^{-1} \cdot{ }^{[26]}$ Furthermore, the $\mathrm{E}_{2 \mathrm{~g}}$ and $\mathrm{A}_{1 \mathrm{~g}}$ modes in the $\mathrm{MoS}_{2} /$ graphene composite materials were significantly red shifted by ca. $4-5 \mathrm{~cm}^{-1}$ compared to pure $\mathrm{MoS}_{2}$, while the $D$, $G$ and $2 D$ bands of graphene were at the same peak positions as the pure graphene. This may be a result of chemical interactions between $\mathrm{MoS}_{2}$ and graphene resulting in changes the electronic band structure of $\mathrm{MoS}_{2}{ }^{[27]}$

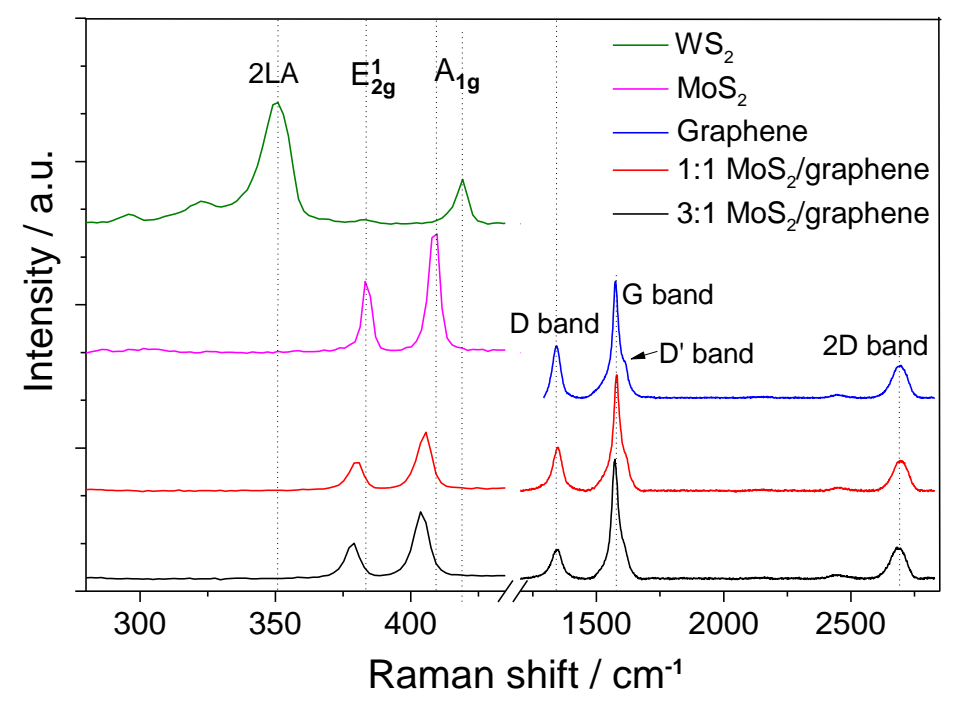

Figure 4. Raman spectra $(532 \mathrm{~nm})$ of the exfoliated materials after self-assembly at the water|DCB interfaces deposited onto a $\mathrm{Si} / \mathrm{SiO}_{2}$ wafer. 
In order to study the morphology of the exfoliated 2D materials, SEM analysis was performed on each of the materials before and after self-assembly at the interface. The SEM micrographs of the three exfoliated materials on PTFE membranes are shown in Figure 5(a, c, and e), as well as micrographs after self-assembly in Figure 5 (b, d, and f). The flake sizes are in the range of $100-300 \mathrm{~nm}$ for $\mathrm{MoS}_{2}$ and $\mathrm{WS}_{2}$, and $500 \mathrm{~nm}$ for graphene, restacking horizontally into a 'paper' like structure ${ }^{[22]}$ with heavy cracking and obvious wrinkles of their surfaces. Interestingly after self-assembly at the interface, the SEM micrographs revealed that $\mathrm{MoS}_{2}$ was agglomerated in the shape of bubbles at interfaces (see Figure S9), while the morphology of $\mathrm{WS}_{2}$ retains the flake-like structure observed prior to assembly, as illustrated in Figure 5(b) and (d), respectively. In addition, the graphene showed flake sizes of ca. 500 nm agglomerated 'edge-to-edge' as shown in Figure 5(f).
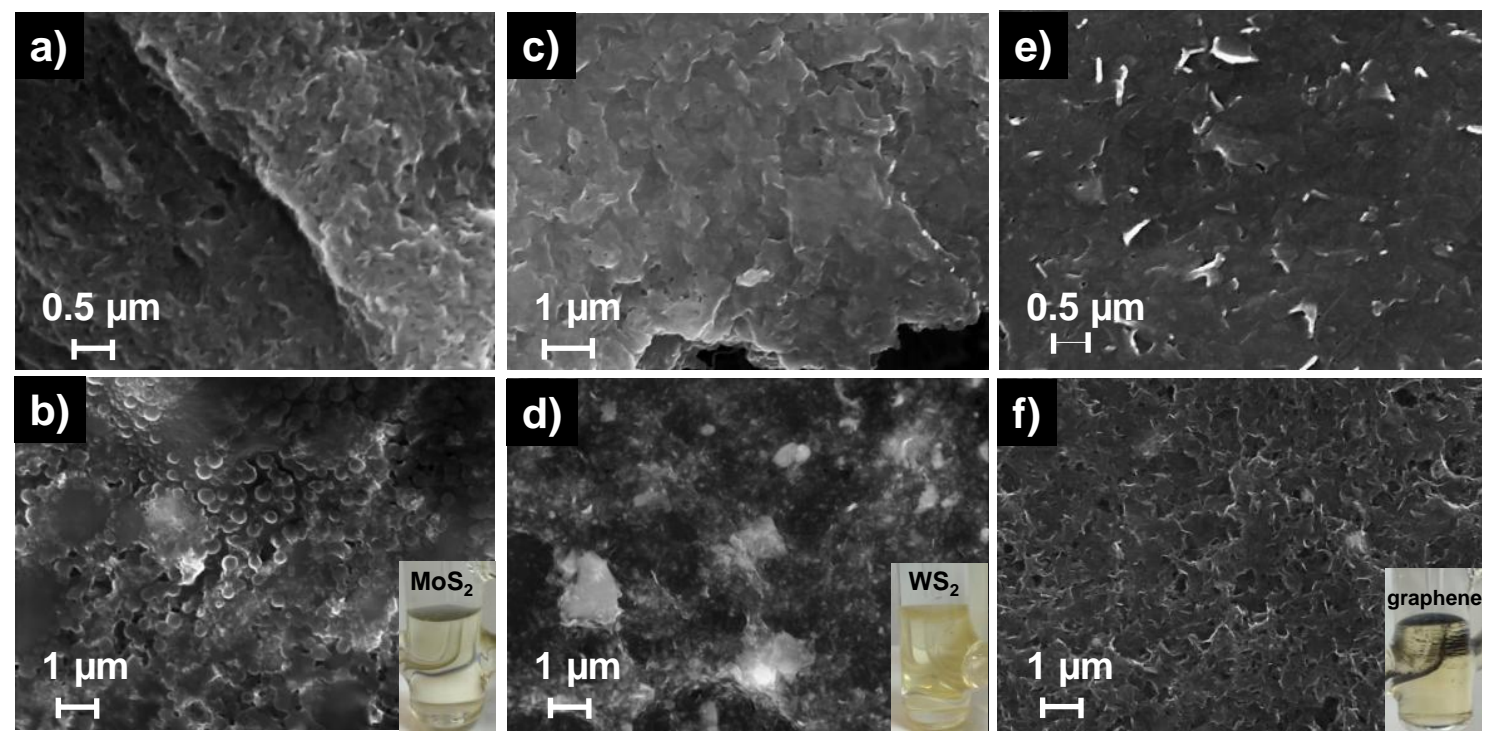

Figure 5. SEM images of (a) the exfoliated $\mathrm{MoS}_{2}$, (c) $\mathrm{WS}_{2}$, and (e) graphene filtered onto PTFE membranes and following self-assembly of (b) $\mathrm{MoS}_{2}$, (d) $\mathrm{WS}_{2}$, and (f) graphene at the water|DCB interface. 
XPS is commonly used to determine the composition and stoichiometry of 2D materials. XPS spectra of $\mathrm{MoS}_{2}$, before and after exfoliation in DCB, are shown in Figure 6(a). The binding energies are calibrated using adventitious carbon $(\mathrm{C} 1 \mathrm{~s})$ at $284.8 \mathrm{eV}$ and the atomic percentage of the peaks were determined by optimised peak fit using a nonlinear Shirley-type background (70\% Gaussian and 30\% Lorentzian line shapes) with the Kratos library. ${ }^{[28]}$ Such fitting of the Mo and $\mathrm{S}$ peaks in the exfoliated $\mathrm{MoS}_{2}$ gave compositions similar to those of the pristine samples, as shown in Figure 6(b-e). However, it can be clearly seen that $\mathrm{Cl} 2 \mathrm{p}$ peaks appeared (at $\sim 200 \mathrm{eV}$ ) after exfoliation, at around 2.6 at $\%$, which is attributed to chlorine from DCB interacting with Mo atoms and causing the significant increase seen in the binding energies of Mo 3p, ca. $3 \mathrm{eV}$ (see Figure 6(b and d)). This can be used to confirm the presence of a new feature attributed to $\mathrm{Cl} 2 \mathrm{p}_{3 / 2}$ within the XPS spectrum. This occurs at a binding energy of $198.9 \mathrm{eV}$, which corresponds to the Mo-Cl bond as shown in Figure S12(a). ${ }^{[29]}$ Moreover, the $\operatorname{MoS}_{\mathrm{x}}$ stoichiometry, determined by atomic percentage, increased from $\mathrm{MoS}_{2.24}$ in bulk to $\mathrm{MoS}_{2.39}$ following exfoliation. ${ }^{[30]}$ This indicated that the exfoliated $\mathrm{MoS}_{2}$ flakes displayed more sulphur-edge.

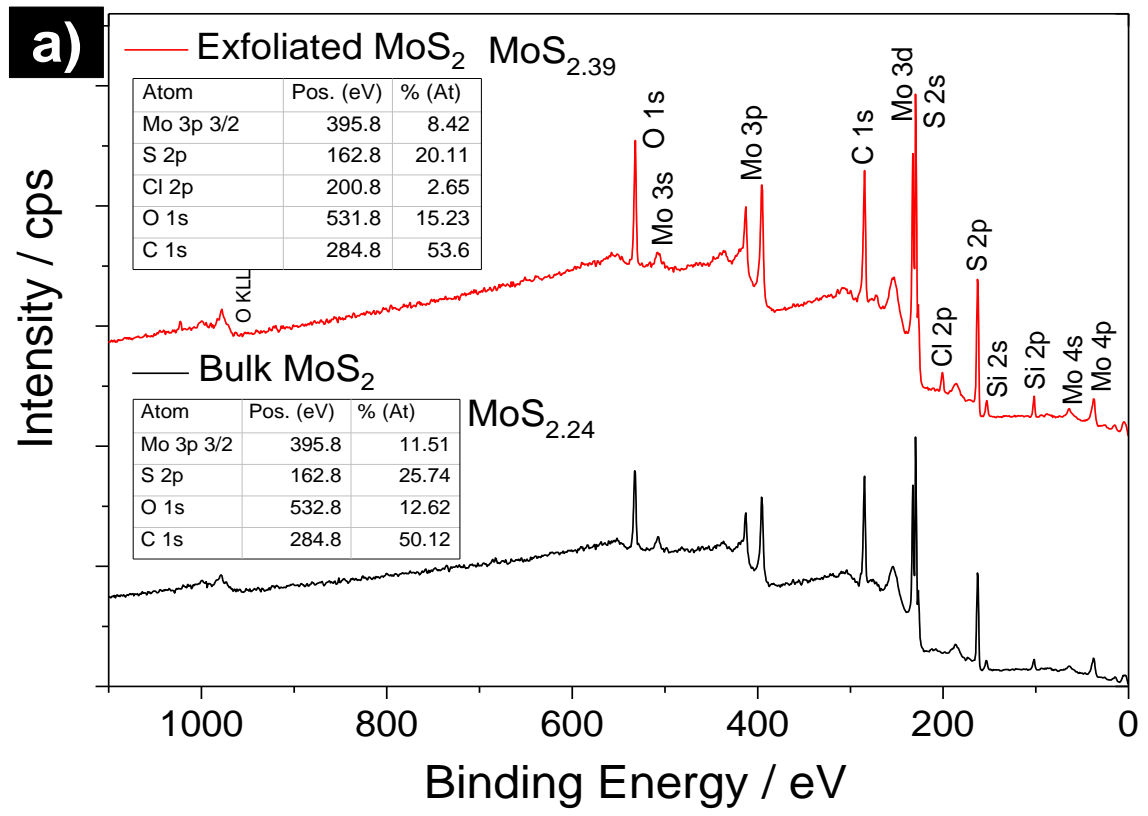



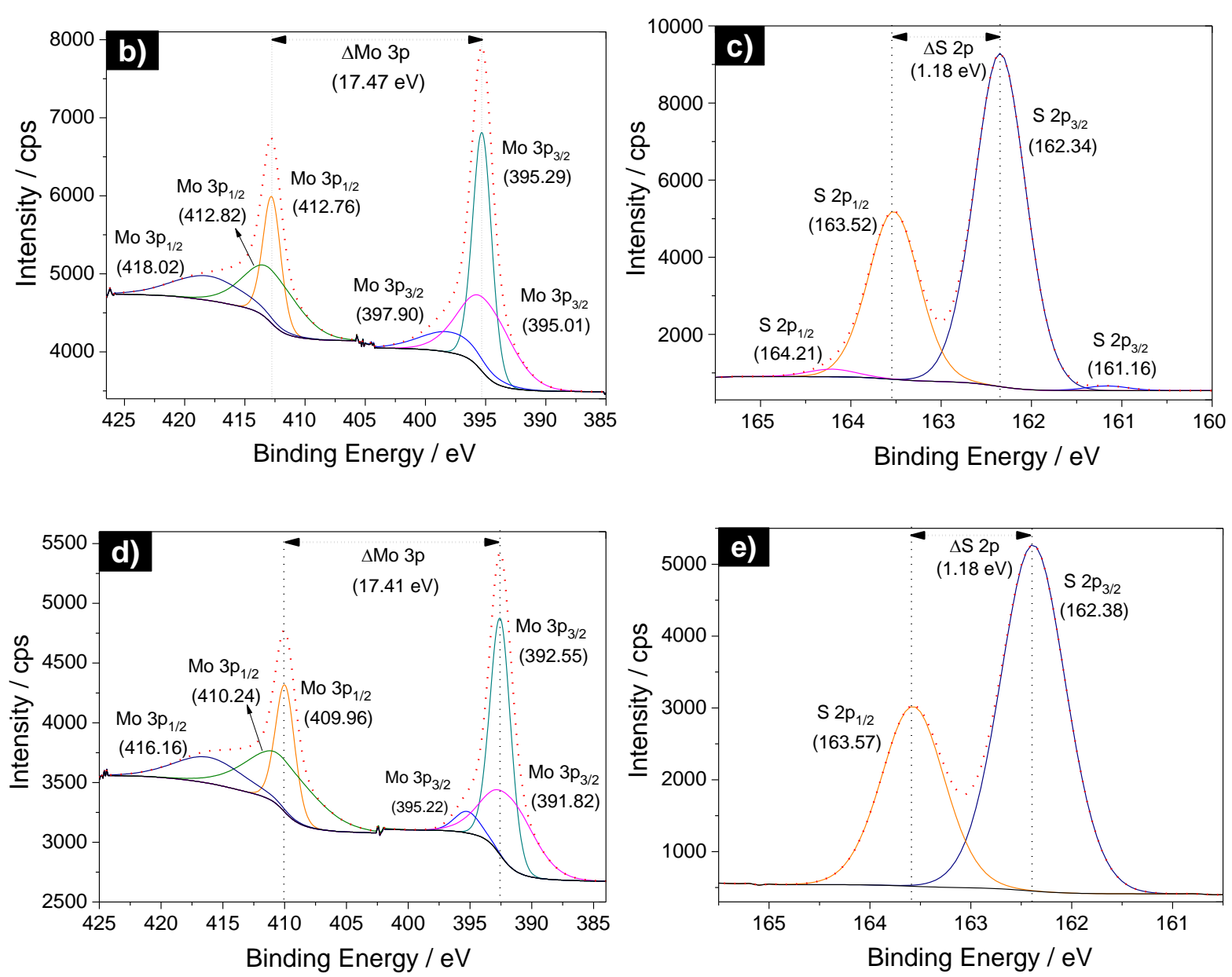

Figure 6. (a) XPS scan analysis of exfoliated and bulk $\mathrm{MoS}_{2}$. High-resolution XPS spectra showing Mo 3p and S 2p shells of (b-c) exfoliated $\mathrm{MoS}_{2}$ and (d-e) bulk $\mathrm{MoS}_{2}$. Each of the fitting peaks is labelled with the corresponding orbital, as well as the binding energy in parentheses. Black solid line, red dot line, and other colours are background, raw data, and fitting peaks, respectively.

The potential windows for cyclic voltammetry performed at the polarised liquid|liquid interfaces are limited by the transfer of supporting electrolyte ions, which in this case was BTPPATFPB (see Figure S1-2). To avoid interference from the oxygen reduction reaction (ORR), all electrochemistry was carried out under an argon atmosphere. The proton transfer reaction at the water|DCB interface was studied in the absence and presence of $\mathrm{MoS}_{2}$ without DcMFc as shown in Figure 7(a-b), respectively. Both systems indicated that the HER onset 
potential at each $\mathrm{pH}$ shifted by $60 \mathrm{mV} / \mathrm{pH}$ in accordance with the Nernst equation. ${ }^{[13 \mathrm{~b}, 31]}$ Interestingly, the onset potential in the presence of the interfacial $\mathrm{MoS}_{2}$ was shifted to more negative potentials by ca. $20 \mathrm{mV}$, as well as the high current density seen at potential of $0.1 \mathrm{~V}$ $\left(\sim 7 \mu \mathrm{A} \mathrm{cm}^{-2}\right)$ compared with blank $\left.(\sim 3 \mu \mathrm{A} \mathrm{cm})^{-2}\right)$ at the same $\mathrm{pH}$. This may be due to the presence of the interfacial $\mathrm{MoS}_{2}$, which leads to a greater surface area (due to the effective increase in roughness of the liquid|liquid interface), which results in more proton transfer at a given potential. In order to produce hydrogen gas, DcMFc was added to the organic phase to act as a reducing agent for the aqueous protons, via:

$$
2 \mathrm{DcMFc}_{(\mathrm{DCB})}+2 \mathrm{H}^{+}{ }_{(\mathrm{aq})} \stackrel{\text { Interfacial catalyst }}{\longrightarrow} 2 \mathrm{DcMFc}^{+}{ }_{(\mathrm{DCB})}+\mathrm{H}_{2(\mathrm{~g})}
$$

Interfacial $\mathrm{MoS}_{2}$ appears to catalyse the $\mathrm{HER}^{[4 \mathrm{~b}, 13 \mathrm{~b}]}$ as shown in Figure 7(c), and evidenced by the absence of a return proton transfer peak compared with the case where only DcMFc is present, which exhibited a reverse voltammetric peak, associated with the (partial) return of the protons to the aqueous phase. Also, the onset potential was shifted to more negative potentials by ca. $40 \mathrm{mV}$ in the presence of $\mathrm{MoS}_{2}$ at the interface (see inset table in Figure 7(c)). Figure 7(d) shows the onset potential of HER catalysed by $\mathrm{MoS}_{2}$ at different aqueous phase $\mathrm{pH}$ values, with a shift of ca. $60 \mathrm{mV} / \mathrm{pH}$, demonstrating that aqueous protons are involved in the voltammetric response. ${ }^{[13 \mathrm{~b}]}$ In addition, voltage sweep rate studies of interfacial $\mathrm{MoS}_{2}$ are illustrated for the HER at $\mathrm{pH} 1$ in Figure 8. The dependence of current on the square root of sweep rate indicate that the kinetics of the proton coupled electron transfer (PCET) process were controlled by diffusion of DcMFc to the reaction site on the interfacial $\mathrm{MoS}_{2}{ }^{[13 \mathrm{a}]}$ (see inset in Figure 8). $\mathrm{WS}_{2}$ and graphene were examined as HER catalysts for comparison with $\mathrm{MoS}_{2}$, their morphologies at the interfaces are shown in Figure S9. The other materials did not perform HER as well as $\mathrm{MoS}_{2}$ at the water|DCB interface because reverse peaks, associated with proton return transfer, were observed in the CVs. 
During electrochemical measurements the films appeared to be stable with respect to agglomeration, as has been noted for similar interfacial assemblies prepared using the organic phase dispersion route adopted here. ${ }^{[12 b, 17]}$
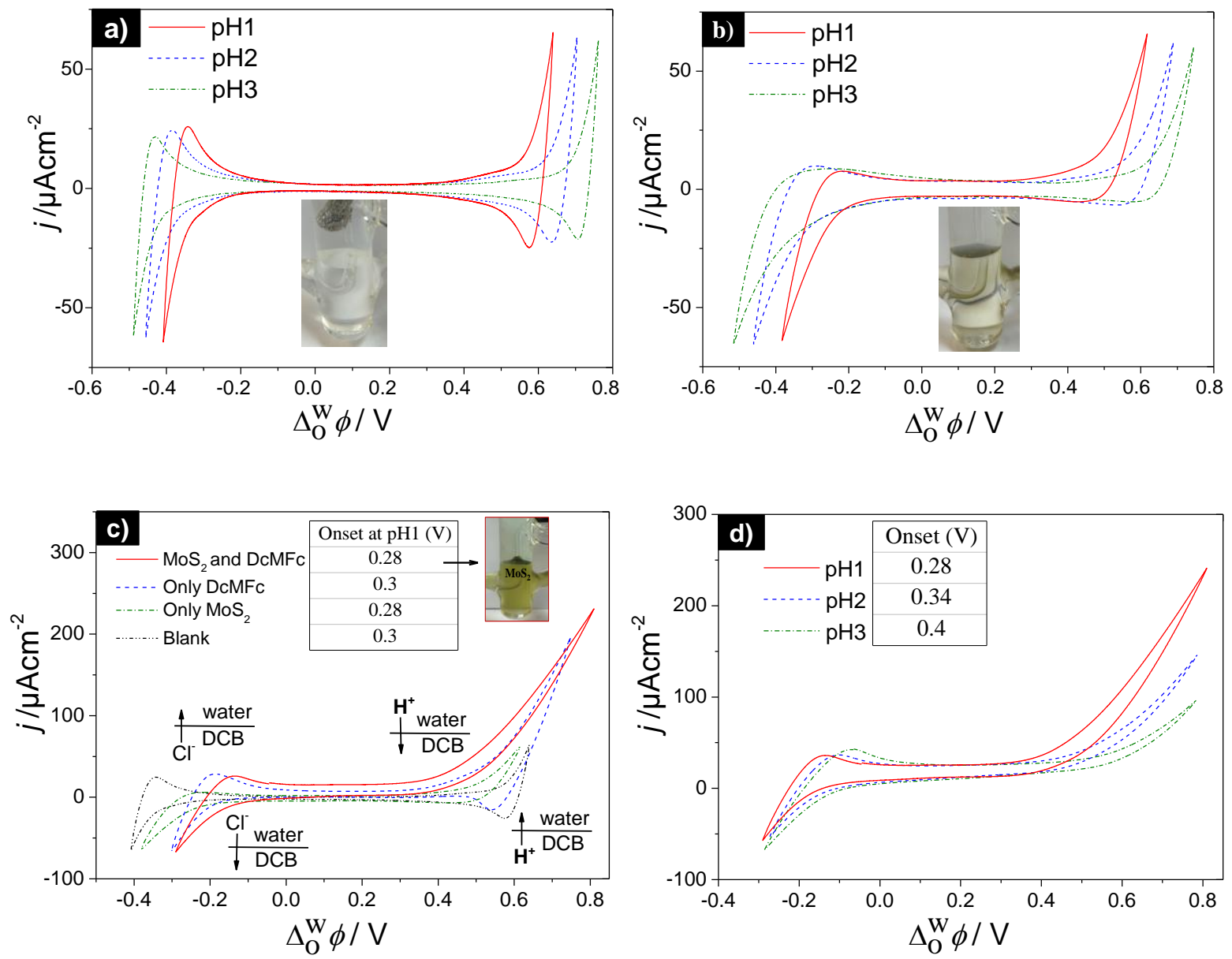

Figure 7. Cyclic voltammetry (CVs) of the proton transfer at water|DCB interfaces under argon: (a) in absence of $\mathrm{MoS}_{2}$ and (b) with $\mathrm{MoS}_{2}$ adsorbed at the interface, in both cases without reducing agent (DcMFc). (c) HER catalysed by $\mathrm{MoS}_{2}$ (red solid line) compared to without catalyst (blue dot line), without DcMFc (green dash line) and blank (black dash dot line), as well as onset potential of each CVs at $\mathrm{pH}$ 1. (d) CVs of HER catalysed by $\mathrm{MoS}_{2}$ at $\mathrm{pH}$ 1-3 with onset potential. All CVs were performed at a scan rate of $50 \mathrm{mV} / \mathrm{s}$. 


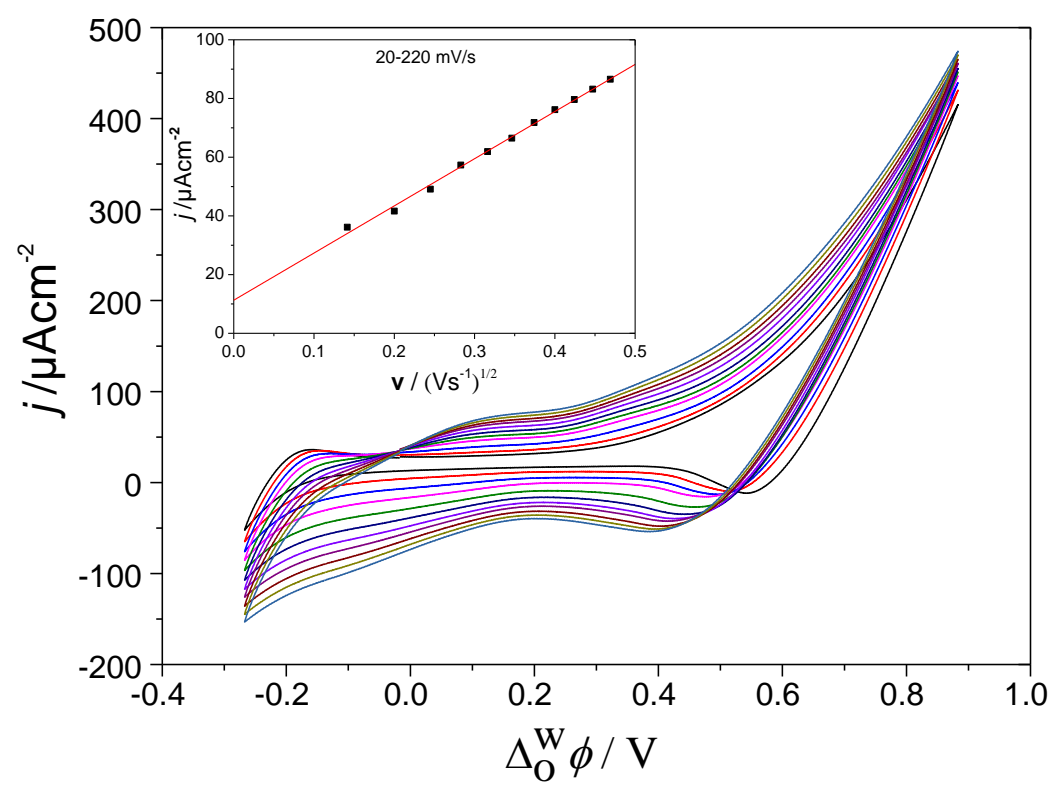

Figure 8. Scan rate studies: voltammetric response from $20-220 \mathrm{mV} / \mathrm{s}$ for HER in the presence of both $\mathrm{DcMFc}$ and $\mathrm{MoS}_{2}$ at $\mathrm{pH}$ 1. Inset: plot of current density $(j)$ versus the square root of the scan rate $(\mathrm{v})$ at $\Delta_{\mathrm{o}}^{\mathrm{W}} \varphi=0.28 \mathrm{~V}$ (i.e. at HER onset potential) from lowest to highest scan rate.

The kinetics of the biphasic HER, in the presence and absence of interfacial catalysts, can be precisely studied by monitoring the evolution of the $\operatorname{DcMFc}^{+}$peak $\left(\lambda_{\max }=779 \mathrm{~nm}\right)$ in the organic phase over time, using UV-visible spectroscopy. ${ }^{13}$ These experiments were carried out in situ under an argon atmosphere using chronoamperometry to step the Galvani potential to $\sim 0.53 \mathrm{~V}$ for 100 mins with constant stirring. Figure 9 shows the formation of hydrogen gas at the ITIES, in the absence and presence of a catalyst, as a function of time. The production of hydrogen is evident from the formation of bubbles at the ITIES. In spite of their catalytic function, hydrogen bubbles were observed apparently beneath the interfacial $\mathrm{MoS}_{2}$, because coalesced bubbles was unable to penetrate through the interfacial $\mathrm{MoS}_{2}$ film as shown in Figure 9(b). 


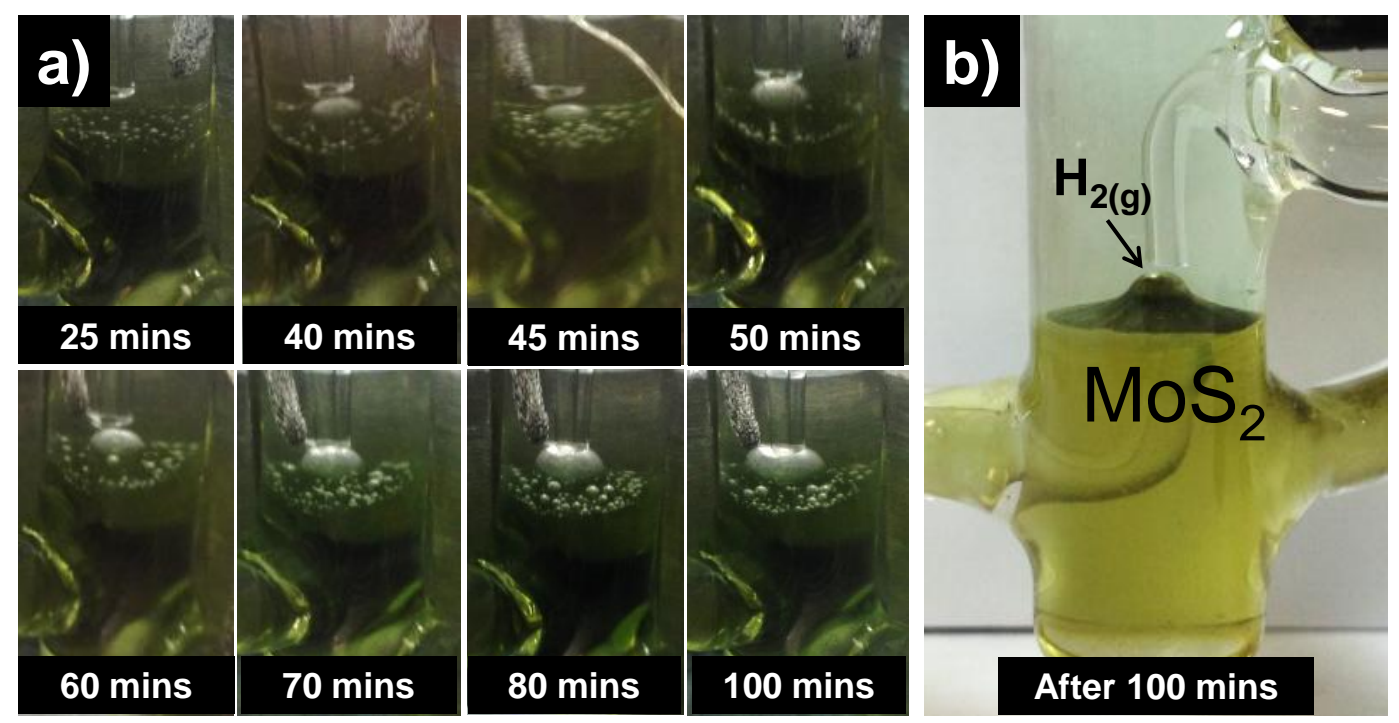

Figure 9. Hydrogen bubbles at (a) the clear ITIES without catalyst and (b) with interfacial $\mathrm{MoS}_{2}$ during application of a ca. $\sim 0.53 \mathrm{~V}$ potential for 100 mins.

In addition, Figure 10(a) shows a kinetic analysis of the HER catalysed by $\mathrm{MoS}_{2}$, $\mathrm{WS}_{2}$, graphene, and their composites at the ITIES, compared to the no-catalyst case. The inset in Figure 10(a) shows a liquid|liquid cell with interfacial $\mathrm{MoS}_{2}$ before and after applying a Galvani potential difference of $+0.53 \mathrm{~V}$ for 100 mins. The amount of hydrogen gas was estimated from the concentration of $\mathrm{DcMFc}^{+}$produced using the stoichiometric reaction (Eq. 1) as shown in Figure 10(b). The rate of HER, v, from Eq. 1 can be written as in the form stated in Eq. 2.

$$
v=-\frac{\mathrm{d}[\mathrm{DcMFc}]}{\mathrm{dt}}=-\frac{\left[\mathrm{H}^{+}\right]}{\mathrm{dt}}=+\frac{\left[\mathrm{DcMFc}^{+}\right]}{\mathrm{dt}}=+2 \frac{\mathrm{d}\left[\mathrm{H}_{2}\right]}{\mathrm{dt}}
$$

Then, the generic rate law of HER catalysed by $\mathrm{MoS}_{2}, \mathrm{WS}_{2}$, and graphene is given by Eq. 3;

$$
\text { Rate }=\mathrm{k}[\mathrm{DcMFc}]^{\mathrm{x}}\left[\mathrm{H}^{+}\right]^{\mathrm{y}}
$$

where $\mathrm{x}$ and $\mathrm{y}$ are reaction orders. Then, $\mathrm{y}$ is 0 (independent of proton concentration) when $\left[\mathrm{H}^{+}\right]>1 \mathrm{mM},{ }^{[4 \mathrm{~b}, 13 \mathrm{a}]}$ whereas $\mathrm{x}$ is assumed to be one, i.e. first-order kinetics prevail in the 
presence of interfacial $\mathrm{MoS}_{2}{ }^{[4 b, 13 b]}$ and $\mathrm{WS}_{2}{ }^{[13 c]}$. Therefore, the rate of reaction for the HER catalysed by $\mathrm{MoS}_{2}, \mathrm{WS}_{2}$ and, graphene can be approximated as a pseudo-first order process:

$$
v=k[\mathrm{DcMFc}]=-\frac{\mathrm{d}[\mathrm{DcMFc}]}{\mathrm{dt}}
$$

where $k$ is the rate constant of the HER. Then, the integrated rate law is stated as shown in Eq. 5.

$$
\ln \frac{[\mathrm{DcMFc}]_{0}}{[\mathrm{DcMFc}]_{0}-\left[\mathrm{DcMFc}^{+}\right]_{t}}=\mathrm{kt}
$$

where $[\mathrm{DcMFc}]_{0}$ is the initial concentration of DcMFc in $\mathrm{DCB}$ and $\left[\mathrm{DcMFc}^{+}\right]_{t}$ is the concentration of $\mathrm{DcMFc}^{+}$at time $t$. Figure 11(a) shows UV-visible spectra for the oxidation of DcMFc (yellow solution with $\lambda_{\max }=425 \mathrm{~nm}$ ) to $\mathrm{DcMFc}^{+}$(green solution with $\lambda_{\max }=779$ $\mathrm{nm}$ ) in the presence of the interfacial $\mathrm{MoS}_{2}$ associated with the production of hydrogen gas. Moreover, rate constants were calculated by fitting the data with Eq. 5 as illustrated in Figure 11(b). Table 2 shows the average rate constants of the HER catalysed by interfacial $\mathrm{MoS}_{2}$, $\mathrm{WS}_{2}$, graphene, and composites, in comparison with the "blank" system. It is clear that interfacial $\mathrm{MoS}_{2}$ provides a catalytic effect towards the HER, with a rate constant approximately 3 times that of the blank. This is attributed to an abundance of active edge sites and the high specific surface area of $\mathrm{MoS}_{2}{ }^{[14,32]}$ at the water|DCB interface. The reaction scheme of the biphasic HER with interfacial $\mathrm{MoS}_{2}$ at polarised water|DCB is shown in Scheme 1. This reaction might be attributed to proton coupled electron transfer (PCET) by protons adsorbed on the interfacial $\mathrm{MoS}_{2}$ surface with the rapid electron transfer from DcMFc rapidly as a heterogeneous process ${ }^{[13 a, 14]}$ hence the absence of a return proton peak in the CV (see Figure 7(c)). 
Moreover, interfacial-adsorbed graphene is able to act as a catalyst as reported recently by Toth et al. ${ }^{[11 e, 33]}$ because of the ability of graphene to pool electrons taken from the reducing agent $(\mathrm{DcMFc})$ and its ability to increase effective reaction cross-section, due to its high conductivity, meaning it acts as a conduit for heterogeneous electron transfer across the ITIES. ${ }^{[17]}$ For these reasons, it was expected that the combination of $\mathrm{MoS}_{2}$ and graphene support would act synergistically and thus improve the catalytic activity, as reported by the Girault group who noted an improvement in the catalytic effect of $\mathrm{MoS}_{2}{ }^{[4 b]}$ and $\mathrm{Mo}_{2} \mathrm{C}^{[13 \mathrm{a}]}$ using conductive carbon substrates, toward HER at the ITIES. Surprisingly, it was found that the $\mathrm{MoS}_{2}$ /graphene composites used here gave a more modest enhancement of the HER than the pure $\mathrm{MoS}_{2}$ (18\% drop in rate). This apparent deleterious effect of graphene on the catalytic performance of $\mathrm{MoS}_{2}$ appears to follow the proportions used to form the films. This suggests that the observed response is a direct combination of the performance of the individual materials rather than an enhancement through the amalgamation of the materials.

One possible explanation for this is the obstruction of the active edge sites of $\mathrm{MoS}_{2}$ by the graphene flakes, which detrimentally affects the rate of HER at the ITIES. The exfoliated $\mathrm{MoS}_{2}$ in this work gave an HER rate constant which was substantially lower (more than a factor of 10 lower) than the value reported by Ge et $a l .{ }^{[4 b]}$ for HER at the ITIES, who used a slightly greater mass of exfoliated $\mathrm{MoS}_{2}$. One factor behind the lower rate constant observed in this case is that the reactions were performed at a lower driving force, an applied Galvani potential (referenced to the $\mathrm{TEA}^{+}$scale) of $+0.53 \mathrm{~V}$ was used to perform HER, whereas Ge $e t$ $a l .{ }^{[4 \mathrm{~b}]}$ used a Galvani potential controlled by the distribution of a common ion of $+0.67 \mathrm{~V}$. This difference in overpotential for the interfacial HER can be corrected from knowledge of the Tafel slope of HER on $\mathrm{MoS}_{2}$. A variety of values have been reported, depending on the phase and basal:edge ratio of $\mathrm{MoS}_{2}$, but using the Tafel slope of $60 \mathrm{mV}$ decade ${ }^{-1}$, as reported by Jaramillo et al. ${ }^{[6]}$ as representative means that the lower applied Galvani potential used 
here should correspond to a 220 -fold reduction in HER, compared to the value reported by Ge et $a l{ }^{[4 \mathrm{~b}]}$ In fact the observation that the rate on exfoliated $\mathrm{MoS}_{2}$ is only twenty times lower than rate constant reported by Ge et al. ${ }^{[4 \mathrm{~b}]}$ suggests that the interfacially-adsorbed material is more active than the aqueous dispersion used by Ge et al. ${ }^{[4 \mathrm{~b}]}$
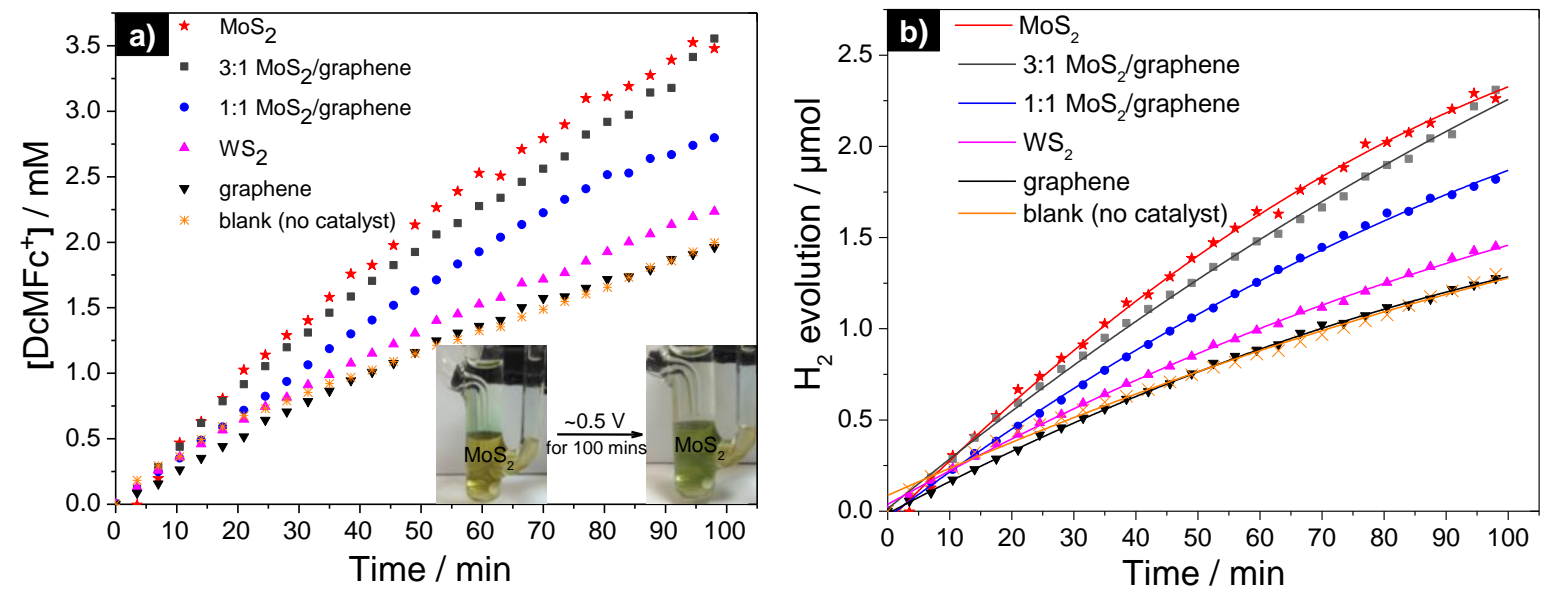

Figure 10. (a) Kinetics of the biphasic HER using chronoamperometry at $\sim 0.53 \mathrm{~V}$ in the presence and absence of interfacial catalysts followed by monitoring the increasing $\mathrm{DcMFc}^{+}$ concentration $\left(\lambda_{\max }=779 \mathrm{~nm}\right)$ over 100 mins. (b) Hydrogen evolution estimated from $\mathrm{DcMFc}^{+}$concentration as a function of time with polynomial fits.
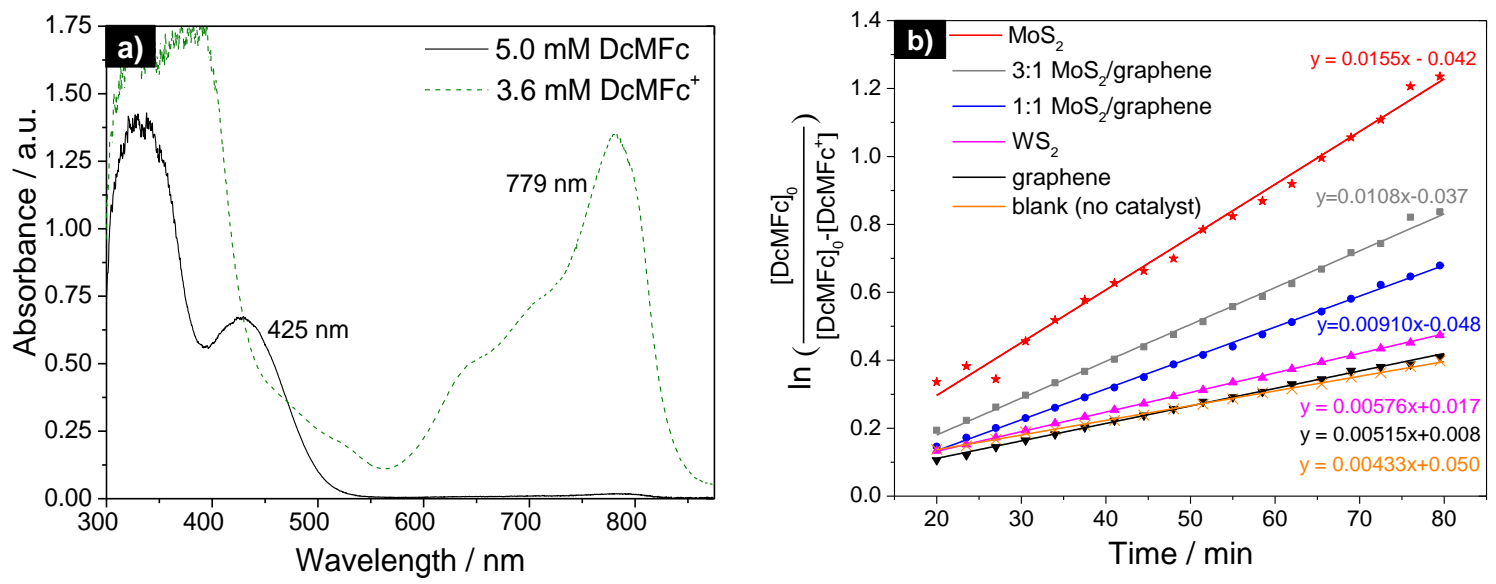

Figure 11. (a) UV-visible absorbance spectra of 5mM DcMFc (black solid line) and $3.6 \mathrm{mM}$ $\mathrm{DcMFc}^{+}$in DCB before and after applying potential for 100 minutes with the interfacial 
$\mathrm{MoS}_{2}$, respectively. (b) Determination of the rate constant $\left(\right.$ slope $=\mathrm{k} / \mathrm{min}^{-1}$ ) by plotting the integrated rate law against with time (20-80min) for the biphasic HER in the absence and presence of catalysts, representing first order reactions.

Table 2. Calculated average rate constants $\left(\mathrm{k} / \mathrm{min}^{-1}\right)$ of the interfacial catalysts for the HER in the presence and absence catalysts.

\begin{tabular}{ccc}
\hline Catalysts & average $\mathrm{k} / \mathrm{min}^{-1}$ & $\mathrm{k} / \mathrm{k}_{\text {blank }}$ \\
\hline $\mathrm{MoS}_{2}$ & $0.0132 \pm 0.063$ & 3.0 \\
$3: 1 \mathrm{MoS}_{2} /$ graphene & $0.0108 \pm 0.022$ & 2.5 \\
$1: 1 \mathrm{MoS}_{2} /$ graphene & $0.0077 \pm 0.028$ & 1.8 \\
$\mathrm{WS}_{2}$ & $0.0058 \pm 0.015$ & 1.3 \\
graphene & $0.0053 \pm 0.003$ & 1.2 \\
blank (no catalyst) & $0.0044 \pm 0.001$ & 1.0 \\
\hline
\end{tabular}

Note: all rate constants were averaged from the three repeated experiments.

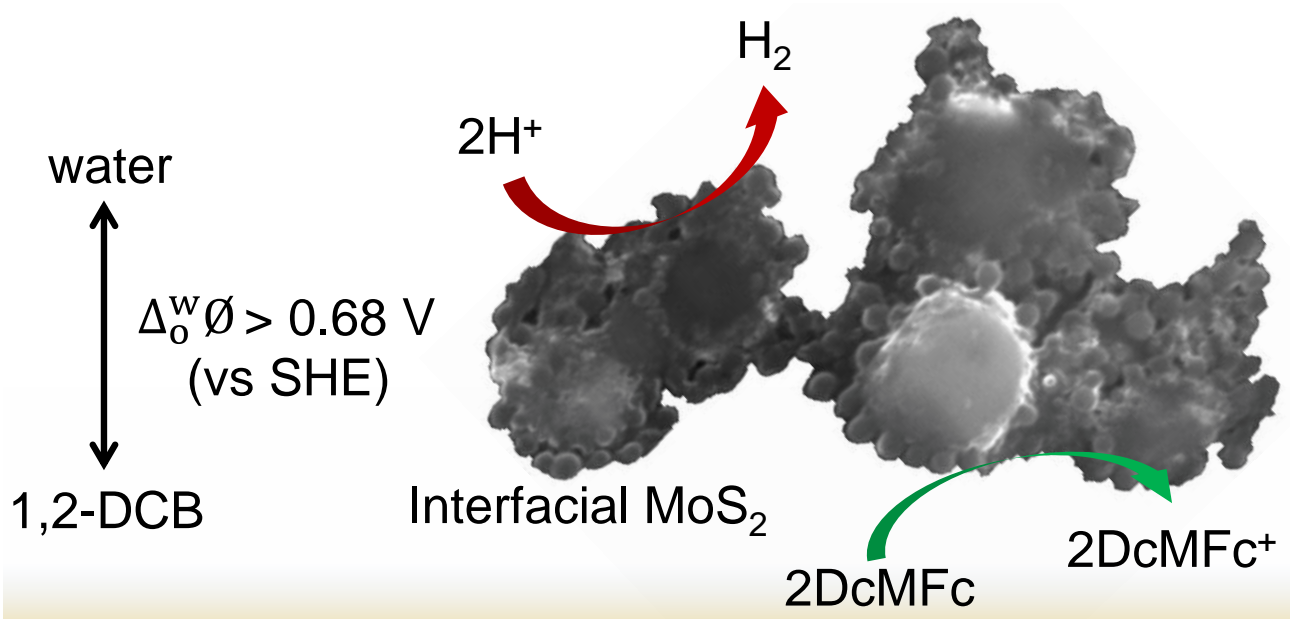

Scheme 1. The mechanism of the biphasic hydrogen evolution reaction in the presence of the exfoliated $\mathrm{MoS}_{2}$ at the water|DCB interface. $\Delta_{o}^{w} \varphi$ is the Galvani potential difference between the water and DCB phases against with the standard hydrogen electrode (SHE). ${ }^{[15]}$ The aqueous and organic phases are coloured blue and yellow, respectively. 


\section{Conclusions}

In the work reported here, $\mathrm{MoS}_{2}, \mathrm{WS}_{2}$, graphene were utilised as $2 \mathrm{D}$ materials for hydrogen evolution at water|DCB interfaces. The materials were exfoliated in DCB which resulted in structures of multi-layer $(\geq 6) \mathrm{MoS}_{2}$, or few-layer flakes for $\mathrm{WS}_{2}$ and graphene. The flake size following exfoliation was measured in the range of a few hundred nanometres for $\mathrm{MoS}_{2}$ and $\mathrm{WS}_{2}$, and ca. $500 \mathrm{~nm}$ for graphene. The $\mathrm{MoS}_{2}, \mathrm{WS}_{2}$, and $\mathrm{MoS}_{2} /$ graphene composites are shown to catalyse the reduction of aqueous protons to molecular hydrogen, using DcMFc as an organic phase electron donor, at the ITIES. From the kinetic studies, the interfacial $\mathrm{MoS}_{2}$ showed the highest rate constant, of $0.0132 \mathrm{~min}^{-1}$, a value estimated to be around 3 times higher than the sample in the absence of a catalyst at the same applied potential difference. This is attributed to the increase of the number of sulphur edge sites on the $\mathrm{MoS}_{2}$ that are reactive toward hydrogen evolution predominantly, corresponding to higher sulphur excess of the exfoliated $\mathrm{MoS}_{2}$ as determined via XPS.

\section{Acknowledgments}

The authors wish to acknowledge funding from the Development and Promotion of Science and Technology Talents Project (DPST), Royal Government of Thailand scholarship. Support from the UK EPSRC (grant reference EP/K016954/1) is also acknowledged. We also thank Samuel G. Booth for stimulating discussion and Dr Peter S. Toth for assistance with early stages of the research.

\section{References}

[1] K. S. Novoselov, A. K. Geim, S. V. Morozov, D. Jiang, Y. Zhang, S. V. Dubonos, I. V. Grigorieva, A. A. Firsov, Science 2004, 306, 666-669. 
[2] a) H. Schmidt, F. Giustiniano, G. Eda, Chem. Soc. Rev. 2015; b) G.-B. Liu, D. Xiao, Y. Yao, X. Xu, W. Yao, Chem. Soc. Rev. 2015, 44, 2643-2663; c) M. Chhowalla, H. S. Shin, G. Eda, L.-J. Li, K. P. Loh, H. Zhang, Nat. Chem. 2013, 5, 263-275.

[3] a) H. Wang, H. Yuan, S. Sae Hong, Y. Li, Y. Cui, Chem. Soc. Rev. 2015, 44, 26642680; b) A. N. J. Rodgers, S. G. Booth, R. A. W. Dryfe, Electrochem. Commun. 2014, 47, 17-20.

[4] a) L. Liao, J. Zhu, X. Bian, L. Zhu, M. D. Scanlon, H. H. Girault, B. Liu, Adv. Funct. Mater. 2013, 23, 5326-5333; b) P. Ge, M. D. Scanlon, P. Peljo, X. Bian, H. Vubrel, A. O'Neill, J. N. Coleman, M. Cantoni, X. Hu, K. Kontturi, B. Liu, H. H. Girault, Chem. Commun. 2012, 48, 6484-6486; c) J. A. Turner, Science 2004, 305, 972-974.

[5] J. K. Nørskov, T. Bligaard, A. Logadottir, J. R. Kitchin, J. G. Chen, S. Pandelov, U. Stimming, J. Electrochem. Soc. 2005, 152, J23.

[6] T. F. Jaramillo, K. P. Jørgensen, J. Bonde, J. H. Nielsen, S. Horch, I. Chorkendorff, Science 2007, 317, 100-102.

[7] Z. Samec, E. Samcová, H. H. Girault, Talanta 2004, 63, 21-32.

[8] a) H. Grégoire, F. Shane, W. M. A. Damien, J. Phys.: Conf. Ser. 2011, 307, 012055;

b) D. W. M. Arrigan, Anal. Lett. 2008, 41, 3233-3252.

[9] a) F. Reymond, H. H. Girault, G. Steyaert, P.-A. Carrupt, B. Testa, Helv. Chim. Acta 1996, 79, 101-117; b) O. Dvořák, V. Mareček, Z. Samec, J. Electroanal. Chem. Interfacial Electrochem. 1991, 300, 407-413.

[10] M. A. Mendez, R. Partovi-Nia, I. Hatay, B. Su, P. Ge, A. Olaya, N. Younan, M. Hojeij, H. H. Girault, Phys. Chem. Chem. Phys. 2010, 12, 15163-15171.

[11] a) F. Ozel, E. Aslan, A. Sarilmaz, I. Hatay Patir, ACS Appl. Mater. Interfaces 2016, 8, 25881-25887; b) I. Hatay, B. Su, F. Li, R. Partovi-Nia, H. Vrubel, X. Hu, M. Ersoz, H. H. Girault, Angew. Chem. 2009, 121, 5241-5244; c) E. Aslan, I. H. Patir, M. Ersoz, Chem. Eur. J. 2015, 21, 4585-4589; d) U. Koelle, P. P. Infelta, M. Graetzel, Inorg Chem 1988, 27, 879-883; e) P. S. Toth, M. Velický, M. A. Bissett, T. J. A. Slater, N. Savjani, A. K. Rabiu, A. M. Rakowski, J. R. Brent, S. J. Haigh, P. O'Brien, R. A. W. Dryfe, Adv. Mater. 2016, 28, 8256-8264.

[12] a) S. G. Booth, R. A. W. Dryfe, J. Phys. Chem. C 2015, 119, 23295-23309; b) A. N. J. Rodgers, M. Velický, R. A. W. Dryfe, Langmuir 2015, 31, 13068-13076.

[13] a) M. D. Scanlon, X. Bian, H. Vrubel, V. Amstutz, K. Schenk, X. Hu, B. Liu, H. H. Girault, Phys. Chem. Chem. Phys. 2013, 15, 2847-2857; b) I. Hatay, P. Y. Ge, H. Vrubel, X. Hu, H. H. Girault, Energy Environ. Sci. 2011, 4, 4246-4251; c) E. Aslan, I. Hatay Patir, M. Ersoz, ChemCatChem 2014, 6, 2832-2835.

[14] X. Bian, M. D. Scanlon, S. Wang, L. Liao, Y. Tang, B. Liu, H. H. Girault, Chem. Sci. 2013, 4, 3432-3441.

[15] P. Peljo, T. Rauhala, L. Murtomäki, T. Kallio, K. Kontturi, Int. J. Hydrogen Energy 2011, 36, 10033-10043.

[16] C. E. Hamilton, J. R. Lomeda, Z. Sun, J. M. Tour, A. R. Barron, Nano Lett. 2009, 9, 3460-3462.

[17] A. N. J. Rodgers, R. A. W. Dryfe, ChemElectroChem 2016, 3, 472-479.

[18] a) P. VANÝSEK, L. B. RAMÍREZ, J. Chil. Chem. Soc. 2008, 53; b) B. Su, H. H. Girault, Z. Samec, 2011.

[19] a) B. Hundhammer, C. Müller, T. Solomon, H. Alemu, H. Hassen, J. Electroanal. Chem. Interfacial Electrochem. 1991, 319, 125-135; b) A. J. Parker, Chem. Rev. 1969, 69, 1-32.

[20] a) J. A. Wilson, A. D. Yoffe, Adv. Phys. 1969, 18, 193-335; b) G. Cunningham, M. Lotya, C. S. Cucinotta, S. Sanvito, S. D. Bergin, R. Menzel, M. S. P. Shaffer, J. N. Coleman, ACS Nano 2012, 6, 3468-3480. 
[21] a) V. H. Pham, T. V. Cuong, S. H. Hur, E. Oh, E. J. Kim, E. W. Shin, J. S. Chung, J. Mater. Chem. 2011, 21, 3371-3377; b) Y. Hernandez, V. Nicolosi, M. Lotya, F. M. Blighe, Z. Sun, S. De, I. T. McGovern, B. Holland, M. Byrne, Y. K. Gun'Ko, J. J. Boland, P. Niraj, G. Duesberg, S. Krishnamurthy, R. Goodhue, J. Hutchison, V. Scardaci, A. C. Ferrari, J. N. Coleman, Nat Nano 2008, 3, 563-568.

[22] M. A. Bissett, S. D. Worrall, I. A. Kinloch, R. A. W. Dryfe, Electrochim. Acta 2016, 201, 30-37.

[23] a) M. A. Pimenta, E. del Corro, B. R. Carvalho, C. Fantini, L. M. Malard, Acc. Chem. Res. 2015, 48, 41-47; b) X. Zhang, X.-F. Qiao, W. Shi, J.-B. Wu, D.-S. Jiang, P.-H. Tan, Chem. Soc. Rev. 2015, 44, 2757-2785; c) A. C. Ferrari, Solid State Commun. 2007, 143, 47-57.

[24] A. Berkdemir, H. R. Gutiérrez, A. R. Botello-Méndez, N. Perea-López, A. L. Elías, C.-I. Chia, B. Wang, V. H. Crespi, F. López-Urías, J.-C. Charlier, H. Terrones, M. Terrones, Sci. Rep. 2013, 3, 1755.

[25] C. Lee, H. Yan, L. E. Brus, T. F. Heinz, J. Hone, S. Ryu, ACS Nano 2010, 4, 26952700.

[26] a) Y. y. Wang, Z. h. Ni, T. Yu, Z. X. Shen, H. m. Wang, Y. h. Wu, W. Chen, A. T. Shen Wee, J. Phys. Chem. C 2008, 112, 10637-10640; b) A. Gupta, G. Chen, P. Joshi, S. Tadigadapa, Eklund, Nano Lett. 2006, 6, 2667-2673.

[27] G. M. Bhalerao, M. K. Singh, A. K. Sinha, H. Ghosh, Phys. Rev. B 2012, 86, 125419.

[28] a) C. T. Smith, M. A. Leontiadou, P. C. J. Clark, C. Lydon, N. Savjani, B. F. Spencer, W. R. Flavell, P. O’Brien, D. J. Binks, J. Phys. Chem. C 2017, 121, 2099-2107; b) M. Velicky, M. A. Bissett, P. S. Toth, H. V. Patten, S. D. Worrall, A. N. J. Rodgers, E. W. Hill, I. A. Kinloch, K. S. Novoselov, T. Georgiou, L. Britnell, R. A. W. Dryfe, Phys. Chem. Chem. Phys. 2015, 17, 17844-17853.

[29] G. F. Khudorozhko, I. P. Asanov, L. N. Mazalov, É. A. Kravtsova, G. K. Parygina, V. E. Fedorov, Y. V. Mironov, J. Struct. Chem. 1995, 36, 948-955.

[30] M. A. Baker, R. Gilmore, C. Lenardi, W. Gissler, Appl. Surf. Sci. 1999, 150, 255-262.

[31] M. Rimboud, C. Elleouet, F. Quentel, J.-M. Kerbaol, M. L'Her, J. Electroanal. Chem. 2008, 622, 233-237.

[32] a) H. Wang, Z. Lu, S. Xu, D. Kong, J. J. Cha, G. Zheng, P.-C. Hsu, K. Yan, D. Bradshaw, F. B. Prinz, Y. Cui, Proc. Natl. Acad. Sci. 2013, 110, 19701-19706; b) J. Xie, H. Zhang, S. Li, R. Wang, X. Sun, M. Zhou, J. Zhou, X. W. Lou, Y. Xie, Adv. Mater. 2013, 25, 5807-5813.

[33] a) P. S. Toth, M. Velický, Q. M. Ramasse, D. M. Kepaptsoglou, R. A. W. Dryfe, Adv. Funct. Mater. 2015, 25, 2899-2909; b) P. S. Toth, Q. M. Ramasse, M. Velicky, R. A. W. Dryfe, Chem. Sci. 2015, 6, 1316-1323. 


\section{Table of contents}

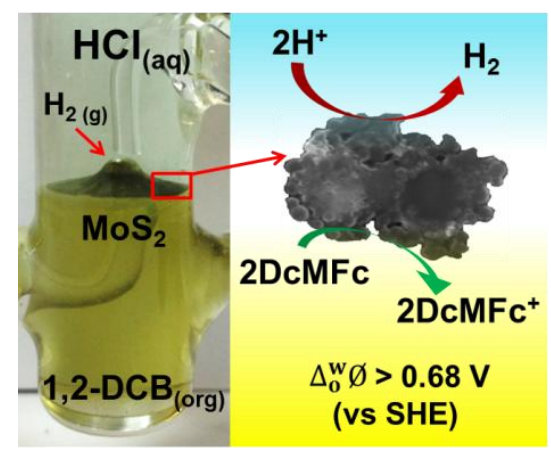

The biphasic hydrogen evolution reaction in the presence of the interfacial $\mathrm{MoS}_{2}$ at the water|DCB interface as an electrocatalytic process for hydrogen evolution reaction is investigated using the Galvani potential difference between the water and DCB phases $\left(\Delta_{O}^{w}\right.$ $\varphi)$ against with the standard hydrogen electrode (SHE). 